\section{References}

1 Cooper AB, Early DF. Evolution in the mental hospital. Br Med $\mathcal{f} 1961$; i:1600-3.

2 Early DF, Magnus RV. Population trends in a mental hospital. Br $\mathcal{F}$ Psychiatry 1966;112:595-601.

3 Early DF, Nicholas $M$. The developing scene: ten-year review of a psychiatric hospital population. Br Med $\mathcal{F} 1971$;iv:793-5.

- Early DF, Nicholas M. Dissolution of the mental hospital: Fifteen years on. Br $\mathcal{F}$ Psychiatry 1977;130:117-22.

W Wansbrough SN. The future of industrial therapy. Lancet 1971 ; i:1009-10.

- Early DF. Twenty years of industrial therapy in Britain. International Journal of Mental Health 1978;6:80-7.

7 Arie T. Guidelines for collaboration between geriatric physicians and psychiatrists in the care of the elderly. Br $\mathcal{F}$ Psychiatry 1979;135:168-9.

8 Department of Health and Social Security. Organisational and management problems of mental illness hospitals. London: DHSS 1979. (Nodder Report.)

- Dodd K, Clarke M, Palmer RL. Misplacement of the elderly in hospitals and residential homes: a survey and follow-up. Health Trends $1980 ; 3$ : 74-6.

10 Department of Health and Social Security. Better services for the mentally ill. Command 6223. London: HMSO, 1975.

11 Mann SA, Cree W. "New" long-stay psychiatric patients. A national sample of 15 mental hospitals in England and Wales, 1972/73. Psycho Med 1976;6:603-16.

12 Eason RJ, Grimes JA. In-patient care of the mentally ill : a statistical study of future provision. Health Trends 1976;8:13-8.

13 SE Thames RHA. Strategies and guidelines for the development of services for the mentally ill. London: SETRHA, 1978. (Consultative document.)

14 Hilton J. How many places? London: National Schizophrenia Fellowship, 1979. (Discussion paper.)

15 Milmo S. MIND welcomes change. On Call 1980 Nov 20:16.

16 Stride R. NHS may set up homes for the elderly. On Call 1980 Nov 20:2.

17 Magnus R. The new chronics. Br F Psychiatry 1967;113:550-6.

18 Babiker IE. Social and clinical correlates of the "new" long-stay. Acta Psych Scand 1980;61:365-75.

(Accepted 6 February 1981)

\title{
Cancer and communication: information-giving in an oncology clinic
}

\author{
PATRICIA M REYNOLDS, R W SANSON-FISHER, A DESMOND POOLE, JENNIFER HARKER, \\ MICHAEL J BYRNE
}

Communication between doctors and patients is attracting increasing attention; yet, while patients place considerable emphasis on their doctors' ability to communicate effectively, ${ }^{1}$ most research studies show that doctors often lack the necessary skills. ${ }^{2-4}$

Communication is especially important in serious illnesses, such as cancer, which are often surrounded by myths and misconceptions. The traditional view among doctors that people with a potentially fatal illness should not be informed of that fact seems to be based on the assumption that such patients do not wish to know that they are dying. ${ }^{4-7}$ Ley's review of published reports showed that the evidence did not support that argument.4 Our investigations were designed, therefore, to find to what extent patients awaiting treatment for cancer wanted information about their illness.

Though the dominant medical attitude seems to be that patients should not be told they have a terminal illness, an alternative view is that the decision should be individually determined, on the basis of each person's intellect, emotional

Sir Charles Gairdner Hospital, Nedlands, Western Australia 6009 PATRICIA M REYNOLDS, MB, FRACP, consultant oncologist, department of medical oncology

MICHAEL J BYRNE, MB, FRACP, consultant oncologist and head of department of medical oncology

University of Western Australia, Nedlands, Western Australia 6009 R W SANSON-FISHER, MPSYCH, PHD, lecturer (behavioural science), department of psychiatry and behavioural science

A DESMOND POOLE, MSC, PHD, associate professor (behavioural science), department of psychiatry and behavioural science

JENNIFER HARKER, BA, research assistant, department of psychiatry and behavioural science state, social and cultural background, family supports, and

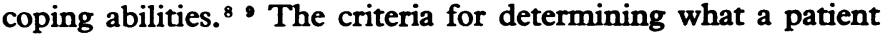
should be told, even after such a detailed assessment, are illdefined; and medical education provides little or no training to equip doctors to assess their patients in these respects. ${ }^{1011} \mathrm{Little}$ wonder, therefore, that in practice doctors tend to follow set routines in three broad categories: always avoid informing patients, always fully inform patients, or only inform those patients who specifically request information.

Each of these approaches is basically "doctor-centred." An alternative strategy is for doctors to inquire specifically what information patients want. In this way patients would be more actively concerned in the communication process. A second aim of our research was, therefore, to examine the practicality and value of adopting such a strategy as a means of determining the amount and type of information patients are given.

The final aim of the studies was to examine the effects of two techniques-explicit categorisation ${ }^{12}$ and providing patients with an audio-recording of the consultation ${ }^{13} 14$-both of which have been claimed to improve patients' recall of information.

\section{Information desired by patients}

The first study examined the nature and extent of the information patients wanted when recently diagnosed as having cancer. The sample consisted of 67 patients with cancers referred for treatment to the medical oncology clinic. During the study all new patients were contacted by a research assistant. Those who agreed to answer questions underwent a structured interview before their first appointment with the oncologist. Of the 67 patients, 56 were aware that they had been diagnosed as having cancer. Three of the remaining 11 reported being unaware of the nature of their illness, while the other eight described specific symptoms but did not appear to know the cause. 
For each specific aspect of their illness about which they were questioned, the numbers of patients who wished to have full information are summarised in table $I$. There were no significant differences between those patients who were aware that they had cancer and those who were apparently unaware of their diagnoses.

TABLE I-Number of 67 patients wishing to obtain full information within each category

\begin{tabular}{lc}
\hline \multicolumn{1}{c}{ Category } & No \\
\hline Diagnosis & 61 \\
Parts of body affected & 60 \\
Symptoms & 62 \\
Investigations, treatments, and side effects & 65 \\
Prognosis & 59
\end{tabular}

\section{Information obtained by patients}

After 25 patients had been interviewed the study was expanded to analyse the information obtained by the patients: the other 42 patients (17 men, 25 women; mean age 52.7, SD 11.5) of the original group of 67 patients were included at this stage. Diagnoses included small cell anaplastic carcinoma of lung (9), adenocarcinoma of breast (17), melanoma (3), malignant lymphoma (5), adenocarcinoma of colon (2), and other (6). After the initial interview with the research assistant patients were randomly allocated to one of three types of "informing consultation." Patients were then seen by one of two oncologists, each of whom saw patients from each of the three groups.

Group 1 patients were informed about their illness and its treatment by using direct questioning and the method of explicit categorisation of presented material described by Ley and his colleagues. ${ }^{12}$ In the consultation the oncologist provided each patient with an information handout, on the first page of which the following categories were listed, and stated: "If you would like to know I will tell you: (1) what is wrong with you and what the diagnosis is; (2) what the treatment will be; (3) what sort of symptoms you may have; (4) what examinations and tests will be necessary; (5) what can be done for any physical discomfort or pain you might experience; and (6) what the outcome might be." Detailed information was then presented under each category heading, provided that, in response to a direct question, the patient indicated that he or she would like to receive information about that aspect of the illness or its treatment. At the end of the consultation patients were given the handout on which the information they wished to receive had been entered during the consultation. They were also provided with a copy of the tape-recording of the consultation.

Group 2 patients were presented with information in an identical manner to that used with group 1 patients, except that they were not given the tape-recording of the consultation.

Group 3 patients acted as a control group and were informed according to the normal practice of the oncologists. These patients were generally given some information about diagnosis, parts of the body affected, proposed treatments, possible side effects, and examinations and tests that would be necessary. Information about response rates to treatment and prognosis were not usually given, unless specifically requested. Any direct questions asked by patients, however, were answered truthfully. Patients in this group did not receive any written information or the tape-recording of the consultation.

After each interview the oncologist immediately recorded all information considered relevant to the patient's illness and treatment. Each item was recorded as a separate fact-every site of the disease, each drug, side effect, etc-to give an estimate of the total number of "facts" potentially available to each patient. No attempt was made to weight facts for their importance.

Five days later each patient was contacted by the independent interviewer and a structured interview was conducted. Patients were again asked how much information they wished to know about each aspect of the illness and also to indicate on a five-point scale how satisfied they were with the amount of information they had received. Furthermore, their actual knowledge about each aspect of the illness and its management was assessed. Six weeks after the initial consultation a further interview, identical to that at five days, was again conducted.

These data were first analysed to determine the extent to which patients received the information they desired. The number of facts desired was calculated from the data sheets-total desired facts being the sum of the facts recorded by the oncologists in every category for which a patient wanted full information. The percentage of these facts known by patients at five-day and six-week follow-up were then calculated from the data obtained by the interviewer. The results are 3 summarised in table II. There were no significant differences between $\stackrel{\varnothing}{ }$ the groups in the amount of information desired, although subjects inc groups 1 and 2 recalled more of the desired information than did those $\widehat{\widehat{O}}$ in the control group (group 3).

TABLE II-Number of "desired facts" and percentage recalled at five-day and six-week follow-up

\begin{tabular}{llrcc}
\hline & & \multicolumn{2}{c}{$\begin{array}{c}\text { Pesired } \\
\text { facts }\end{array}$} & \multicolumn{2}{c}{ Five days } & Six weeks \\
\cline { 4 - 5 } & & 29.6 & 70.9 & 73.5 \\
Group 1 & Mean & 5.8 & 18.5 & 14.8 \\
Group 2 & Mean & 28.1 & 66.5 & 64.3 \\
Group 3 & SD & 5.9 & 14.0 & 12.6 \\
& Mean & 29.9 & 48.3 & 55.4 \\
& SD & 5.3 & 11.9 & 10.8 \\
\hline
\end{tabular}

To seek to investigate the basis for these differences the data were further analysed by determining the number of presented facts-those. actually presented to each patient during the informing consultation ${ }_{\infty}^{N}$ obtained from the tape-recordings of those consultations. Again each? discrete fact was treated as a separate item, and no attempt was mades to weight facts according to importance. Table III summarises the number of facts actually communicated to the members of the three groups.

TABLE III-Number of "presented facts" and presented facts as a percentage of desired facts

\begin{tabular}{llrc}
\hline & & $\begin{array}{c}\text { Presented } \\
\text { facts }\end{array}$ & $\begin{array}{c}\text { Percentage } \\
\text { of desired } \\
\text { facts }\end{array}$ \\
\hline Group 1 & Mean & $29 \cdot 6$ & $100 \cdot 0$ \\
Group 2 & Mean & 5.8 & -10.0 \\
Group 3 & SD & 5.9 & $100 \cdot 0$ \\
& Mean & 18.2 & 60.9 \\
& SD & 5.3 & 7.4
\end{tabular}

TABLE IV-Number of presented facts and amount recalled at five-day and six-week follow-up

\begin{tabular}{|c|c|c|c|c|}
\hline \multirow{2}{*}{ Group } & & \multirow[b]{2}{*}{$\begin{array}{l}\text { Presented } \\
\text { facts }\end{array}$} & \multicolumn{2}{|c|}{ Recalled at } \\
\hline & & & $\begin{array}{c}\text { Five days } \\
\text { No }(\%)\end{array}$ & $\begin{array}{l}\text { Six weeks } \\
\text { No }(\%)\end{array}$ \\
\hline Experimental & $\begin{array}{l}\text { Mean } \\
\text { SD }\end{array}$ & $\begin{array}{r}28.9 \\
5.8\end{array}$ & $\begin{array}{r}19 \cdot 5(68 \cdot 7) \\
5 \cdot 7(16 \cdot 3)\end{array}$ & $\begin{array}{r}19 \cdot 6(68 \cdot 9) \\
5 \cdot 1(14 \cdot 1)\end{array}$ \\
\hline Control & $\begin{array}{l}\text { Mean } \\
\text { SD }\end{array}$ & $\begin{array}{r}18 \cdot 2 \\
5 \cdot 3\end{array}$ & $\begin{array}{r}14.9(79 \cdot 7) \\
4.0(16.6)\end{array}$ & $\begin{array}{r}15.9(84.4) \\
4.3(16.5)\end{array}$ \\
\hline
\end{tabular}

Patients in groups 1 and 2, who were informed using direct questioning and explicit categorisation, received similar amounts of information $(t(26)=0.6784 ; \mathrm{NS})$. Group 3 patients, informed according to the customary practice of the oncologists, received significantly fewer facts than those in either group $1(t(26)=5.4290 ; \mathrm{p}<0.001)$ or group $2(t(26)=4.6709 ; \mathrm{p}<0.001)$. This occurred despite the fact that there were no significant differences between the groups in terms of the amount of desired information (table III). Thus, while those patients ${ }^{+}$ informed using direct questioning and explicit categorisation (groupso 1 and 2) were presented with all desired information, the controb patients (group 3) only received an average of $60.9 \%$ of desired facts

Use of explicit categorisation and the provision of written and tape $\frac{}{\mathbb{D}}$ recorded material has been claimed to help patients' recall of information. ${ }^{12-14}$ The amount of presented information recalled by members of our groups was, therefore, compared. Table IV summarise 8 the percentage and average number of presented facts recalled by the experimental (groups 1 and 2) and control patients at the two follow- 
up interviews. From this it can be seen that the control group patients actually recall a greater percentage of presented facts than the experimental group patients (five days: $t(40)=2.0637 ; \mathrm{p}<0.05$; six weeks: $t(40)=3.2503 ; \mathrm{p}<0.01)$.

At both the five-day and six-week interviews each patient was asked to indicate, on a five-point scale, how satisfied they were with the information they had received. These data (table V) show that patients in all three groups reported being highly satisfied. There were no significant differences between the groups.

TABLE $\mathrm{v}-$ Reported satisfaction at five-day and six-week follow-up (maximum score $=5$ )

\begin{tabular}{llccc}
\hline & & \multicolumn{3}{c}{ Group } \\
\cline { 3 - 5 } & & 1 & 2 & 3 \\
\hline Five-day follow-up & Mean & 4.43 & $4 \cdot 29$ & 4.43 \\
Six-week follow-up & SD & 0.65 & 0.73 & 0.65 \\
& Mean & $4 \cdot 28$ & 4.21 & 3.93 \\
& SD & 0.61 & 0.58 & 0.73 \\
\hline
\end{tabular}

\section{Discussion}

Asking patients what they wanted to know about their illness and treatment, combined with the use of explicit categorisation, resulted in patients receiving significantly more of the facts they wanted than simply informing patients without using these techniques. Furthermore, since the experimental procedure gave patients more information they also recalled more of the facts presented to them-though the procedures did not increase the percentage of information recalled. The value of explicit categorisation seems, then, not so much to improve the proportion of the information that patients subsequently recall but rather that, when combined with direct questioning, it ensures that patients are presented with more of the information they wish to receive. As such the technique merits further investigation.

Giving the patients tape-recordings of their consultations did not enhance recall when compared with the use of explicit categorisation alone. Nevertheless, at the follow-up interviews patients who had received the tape-recordings said they had found them of value. According to their self-reports, 13 of the 14 patients listened to their recordings at least once; and the 14th said that her husband and other members of her family had listened to the tape in order to understand her illness better. The tape-recordings were also used for this purpose by more than half the patients.

A surprising finding was the lack of any significant differences between the control group and the intervention groups in terms of satisfaction with the amount of information received. As the patients in the former group received, on average, less than twothirds of the information they wanted they might have been expected to have expressed greater dissatisfaction. Since, however, a global assessment of satisfaction was undertaken no attempt was made to relate satisfaction levels with specific aspects of information which may, or may not, have been received. Perhaps more importantly, the patients may have been reluctant to express dissatisfaction about the information given by their doctors, since it has been shown that, in general, patients are extremely reluctant to make negative or critical comments to any person concerned in their management. Many patients believe that they must be seen by therapeutic staff as non-demanding, non-complaining, non-assertive, and compliant if they are to receive optimal attention. ${ }^{15}$

The results of our investigations are consistent with reported research in indicating that most patients with a potentially terminal disease wish to be fully informed about their illness and its management. ${ }^{4}$ Nevertheless, not all patients wish to be told about all aspects of their illness. While most patients would be appropriately informed if a routine of providing full information to all patients was adopted, such a strategy would still result in some patients being provided with information they did not wish to have. Asking patients the areas in which information is desired may be an effective and pragmatic means of determining what information patients wish to be given. In our study when this technique was combined with explicit categorisation the patients received all the information they wanted-and without extensive training of the doctors concerned. Indeed, the fact that the same oncologists presented information to patients in all three groups, but provided more information when using explicit categorisation, indicates that doctors can readily use these techniques.

The help of Ms Sally Mullighan, who interviewed the patients, is gratefully acknowledged. The research was supported by a grant from the Cancer Council of Western Australia.

\section{References}

1 Congalton AA. Public evaluation of medical care. Med f Aust 1969 ;2: 1165-71.

${ }^{2}$ Cartwright A. Human relations and hospital care. London: Routledge and Kegan Paul, 1964

${ }^{3}$ Korsch BM, Gozzi EK, Francis V. Gaps in doctor-patient communication -I. Doctor-patient interaction and patient satisfaction. Paediatrics $1968 ; 42: 855-71$

4 Ley P. Psychological studies of doctor-patient communication. In: Rachman S, ed. Contributions to medical psychology. Vol 1. Oxford: Pergamon Press, 1977:9-42.

${ }^{5}$ Brim OG, Freeman HE, Levine S, Scotch NA, eds. The dying patient. New York: Russell Sage Foundation, 1970.

${ }^{6}$ Cartwright A, Hockey L, Anderson JL. Life before death. London: Routledge and Kegan Paul, 1973.

7 Glaser BG, Strauss AL. Awareness of dying. Chicago: Aldine, 1965.

8 Bahnson CB. Psychologic and emotional issues in cancer: The psychotherapeutic care of cancer patients. Semin Oncol 1975;2:293-309.

${ }^{9}$ Holland JF. Psychologic aspects of cancer. In: Holland JF, Frei E, eds. Cancer medicine. Philadelphia: Lea and Febiger, 1973:991-1021.

${ }^{10}$ Krant MJ. Problems of the physician in presenting the patient with the diagnosis. In : Cullen JW, Box BH, Isom PN, eds. Cancer: the behavioral dimensions. New York: Raven Press, 1976:269-74.

11 Poole AD, Sanson-Fisher RW. Understanding the patient: A neglected aspect of medical education. Soc Sci Med 1979;13A:37-43.

12 Ley P, Bradshaw PW, Eaves DE, Walker CM. A method of increasing patients' recall of information presented to them. Psychol Med 1973;3: 217-20.

${ }^{13}$ Butt HR. A method for better physician-patient communication. Ann Intern Med $1977 ; 86: 478-80$.

14 Rosenbaum EH. Oncology/haematology and psychosocial support of the cancer patient. In: Garfield CA, ed. Psychosocial care of the dying patient. New York: McGraw-Hill, 1978:169-84.

15 Nehring V, Geach B. Patients evaluation of their care: why they don't complain. Nursing Outlook 1973;21:317-21.

(Accepted 3 March 1981)

What are the likely causes of hypoplastic anaemia in a patient living in India; what investigations should be conducted?

No statistics are available to indicate the prevalence of aplastic anaemia nor its most frequent causes in patients living in India. There appears to be a considerable variation between different populations throughout the world, but this may reflect differences in the frequency of diagnosis and reporting rather than in true incidence. Exposure to drugs, such as chloramphenicol, phenylbutazone (Butazolidin) antiepileptics, and insecticides, which together possibly account for about half the cases in Britain are probably more important in areas where the use of these substances is less strictly controlled. The remainder may result from unidentified infection; hepatitis is endemic in most tropical countries and may account for some cases. Investigations should include bone marrow trephine biopsy, possibly of samples taken from more than one site. Marrow activity can be measured by ferrokinetic studies, but these are available in only a few centres. Similarly, where facilities are available, patients with aplastic anaemia and their siblings may be HLA typed with a view to bone marrow transplantation. 